\title{
COMPASSION FATIGUE, COMPASSION SATISFACTION, AND BURNOUT: FACTORS IMPACTING A PROFESSIONAL'S QUALITY OF LIFE
}

\author{
GINNY SPRANG and JAMES J. CLARK \\ College of Social Work, University of Kentucky, Lexington, Kentucky, USA
}

ADRIENNE WHITT-WOOSLEY

University of Kentucky, Lexington, Kentucky, USA

\begin{abstract}
This study examined the relationship between three variables, compassion fatigue (CF), compassion satisfaction (CS), and burnout, and provider and setting characteristics in a sample of 1,121 mental health providers in a rural southern state. Respondents completed the Professional Quality of Life Scale as part of a larger survey of provider practice patterns. Female gender was associated with higher levels of CF, and therapists with specialized training in trauma work reported higher levels of CS than nonspecialists. Provider discipline proved to be an important factor, with psychiatrists reporting higher levels of CF than their non-medical counterparts. When providers were compared using rural, urban, and rural with urban influence classifications, the most rural providers reported increased levels of burnout but could not be distinguished from their colleagues on the CF and CS subscales. Important practice, education, and policy implications are noted for a multidisciplinary audience.
\end{abstract}

American author James Baldwin (1963) wrote, "One can give nothing whatever without giving oneself, that is to say risking oneself" (p. 100). Risking exposure to vicarious trauma is an inherent part of the process when working with traumatized persons. The empirical literature has documented mental health consequences of professionals' exposure to trauma patients, responses that differ depending upon individual and contextual characteristics specific to the provider and the practice setting. This study explores variables that might influence such responses to vicarious exposure to traumatic stress by examining compassion fatigue $(\mathrm{CF})$, compassion

Received 10 January 2007; accepted 23 January 2007.

Address correspondence to Ginny Sprang, University of Kentucky, 3470 Blazer Parkway, Suite 100, Lexington, KY 40509. E-mail: sprang@uky.edu 
stress (CS), and burnout among mental health professionals in a rural state. We also explore the individual, occupational, and environmental factors that might impact the ways these conditions are expressed.

\section{Literature Review}

An expanding number of studies are examining the phenomena of $\mathrm{CF}$ and burnout in the helping professions. Early studies of workrelated stresses were first conducted in business and industry, and subsequently in the human service professions. Maslach (1982) defined burnout as "a syndrome of emotional exhaustion, depersonalization, and reduced personal accomplishment" (p. 3) characterized by cynicism, psychological distress, feelings of dissatisfaction, impaired interpersonal functioning, emotional numbing, and physiological problems (Fothergill, Edwards, \& Burnard, 2004). Burnout's etiology is not significantly associated with worker countertransference or reactions to traumatic client material but is associated with other workplace characteristics, such as caseload size and institutional stress (Stamm, 1997).

McCann and Pearlman (1990a) expanded discussions of countertransference reactions to include the term vicarious traumatization (VT), which describes the impact of repeated empathic engagement with trauma survivors and associated cognitive, schematic, and other psychological effects. McCann and Pearlman (1990b) and Pearlman and Saakvitne (1995) identified the potential for disruptions in therapists' experiences of safety, trust, power, esteem, intimacy, independence, and control. Associated symptomatology includes anxiety, disconnection, avoidance of social contact, becoming judgmental, depression, somatization, and disrupted beliefs about self and others (Cunningham, 2003; Pearlman \& Saakvitne, 1995).

CF signifies more progressed psychological disruptions. This term can be used interchangeably with secondary traumatic stress disorder (STSD) and is considered to be less stigmatizing (Figley, 1995). The proposed continuum of responses ranges from compassion satisfaction to compassion stress and ends with CF (Figley, 1995; Stamm, 2002b). Figley's causal compassion stress and fatigue model $(1995,2002 a, 2002 b)$ points to the influence of nine variables implicated in the development of compassion fatigue, including 
those related to traumatic material exposure and clinicians' capacity for empathic engagement. He describes two positive coping variables (sense of achievement and emotional disengagement), while prolonged exposure, traumatic recollections, and life disruption exacerbate stress reactions and may lead to the development of compassion fatigue.

Literature reviews of work-related traumatic stress studies reveal myriad terms to describe similar phenomena, leading Stamm (1997) to opine that the controversy regarding secondary trauma is not its existence but what it should be called. Studies reflect commonalities and links among CF, VT, and secondary traumatic stress (STS), so it is necessary to consider all empirical work regarding these concepts (Adams, Matto, \& Harrington, 2001; Jenkins \& Baird, 2002).

Few epidemiological studies exist regarding CF or secondary trauma among the various groups of helping professionals routinely exposed to trauma in the course of their work. Research on STS symptomatology in child protective service (CPS) workers suggests that this type of work carries high risk for transmission of traumatic stress symptomatology (Dane, 2000; Pryce, Shackelford, \& Pryce, 2007). Cornille and Meyers (1999) found 37\% of study participants exhibited clinically significant distress related to CPS work. A study of community mental health workers found that $17 \%$ met criteria for STSD and $18 \%$ exhibited significant but subclinical levels of psychopathology (Meldrum, King, \& Spooner, 2002). Higher distress levels were found in studies of disaster response teams (Holtz, Salama, Cardozo, \& Gotway, 2002). Following the Oklahoma City bombing, $64.7 \%$ of trauma workers reported significant traumatic stress (Wee \& Meyers, 2002). A study of responders to the $9 / 11$ attacks found $27 \%$ at extremely high risk, $11.7 \%$ at high risk, and $15.4 \%$ at moderate risk for developing CF (Roberts, Flannelly, Weaver, \& Figley, 2003).

Empirical studies of burnout revealed it as an especially prevalent condition among helping professionals (Maslach \& Jackson, 1984), with mental health professionals demonstrating higher levels of burnout than primary health care workers (Imai, Nakao, Tsuchiya, Kuroda, \& Katon, 2004; Korkeila et al., 2003). Notably, public-sector mental health providers were at higher burnout risk compared to their private-sector counterparts (Melamed, Szor, \& Bernstein, 2001; Vredenburgh, Carlozzi, \& Stein, 1999). 
Studies have indicated variables serving as risk or protective factors for STS, CF, or burnout. As age increased, risk for STS, VT, and burnout decreased (Adams et al., Harrington, 2001; Nelson-Gardell \& Harris, 2003; Vredenburgh et al., 1999), and some studies suggested that females were at significantly greater risk for STS and VT (Brady et al., 1999; Kassam-Adams, 1999; Meyers \& Cornille, 2002). Education mitigated burnout (Abu-Bader, 2000), and years of professional experience were associated with a decreased potential for VT (Cunningham, 2003; Pearlman \& MacIan, 1995). Another significant variable, personal trauma history, was associated with increased risk for STS or VT (Cunningham, 2003; Nelson-Gardell \& Harris, 2003), though some studies suggest that personal coping styles and the ability to construct meaning in the face of stressful experiences may be truer determinants of Professionals' emotional functioning (Follette, Polusny, \& Milbeck, 1994; Ortlepp \& Friedman, 2001). Researchers have also found that specialized training can serve a protective function for trauma counselors (Ortlepp \& Friedman, 2002). Another study examined the experiences of STS across mental health disciplines (psychologists, social workers, counselors) but did not find that profession was a predictor of STS (Creamer \& Liddle, 2005).

Exposure factors such as long work hours or length of assignment and caseloads with high percentages of trauma patients have been associated with an increased incidence of STS and CF (Boscarino, Figley, \& Adams, 2004; Creamer \& Liddle, 2005; Meyers \& Cornille, 2002). Organizational factors such as supportive work environments and adequate supervision were noted to mitigate the incidence of STS and burnout (Boscarino et al., 2004; Korkeila et al., 2003; Ortlepp \& Friedman, 2002; Webster \& Hackett, 1999). Autonomy and control seem to be mitigating factors for burnout (Abu-Bader, 2000; Vredenburgh et al., 1999), while access to sufficient resources mitigated both burnout and STS (Abu-Bader, 2000; Ortlepp \& Friedman, 2001).

Workers with high caseloads of survivors of violent or humaninduced trauma (especially against children) seemed to be at greater risk for CF and STS (Creamer \& Liddle, 2005; Cunningham, 2003). A study of mental health workers found that STS symptomatology rates were higher for rural providers when compared to their urban counterparts (Meldrum et al., 2002). Rohland (2000) found that burnout among mental health directors did not 
seem to be influenced by rurality, but he studied only a small sample of nonclinicians.

In order to address the complexity of these phenomena, our study explores the degree to which $\mathrm{CF}$, CS, and burnout vary as a function of provider characteristics such as age, gender, educational level, licensure, years of experience, setting, and whether or not the individual has specialized trauma training. Contextual variables such as organizational type and setting are also considered.

\section{Method}

\section{Sample}

A total of 6,720 licensed or certified behavioral health providers (psychologists, psychiatrists, social workers, marriage and family therapists, professional counselors, and drug and alcohol counselors) currently practicing in a rural southern state were invited to participate in the study. Individuals who were licensed by more than one board were counted only once, leaving a useable pool of 5,752 potential participants.

The remaining pool of providers received a mailed survey at their place of residence along with a self-addressed postage-paid return envelope, a coupon for free training, and an informed consent document that outlined the purpose of the study, the potential benefits and risks of participation, and contact information. Return of the survey indicated the provision of informed consent. A total of 1,121 completed questionnaires were returned, which constituted $19.5 \%$ of the viable candidates for inclusion. Although response rates to mailed surveys of $10 \%-25 \%$ are common (Fox, Crask, \& Kim, 1988), the rate of response to this study may have been higher if budgetary restraints had not prohibited follow-up reminders or remailings.

\section{Measurement}

The instrument used in this study was a 102-item survey designed to solicit information about the providers' practice methods, their use of evidenced-based practices, their knowledge of event-specific responses in various populations (rural, children, the elderly), barriers to effective treatment, and levels of compassion fatigue, 
compassion satisfaction, and burnout. This article deals with a subset of a larger study (Sprang, Craig, \& Clark, 2006) and specifically explores the respondents' professional quality of life and levels of compassion fatigue, compassion satisfaction, and burnout.

The Professional Quality of Life Scale (ProQOL) (Stamm, 2002b), a 30-item self-report measure, assesses risk of CF, potential for CS, and risk of burnout. Higher scores on the CF subscale (10 items) indicate the respondent is at higher risk for compassion fatigue. Higher scores on the CS subscale (10 items) indicate the respondent is experiencing better satisfaction with his or her ability to provide care (e.g., caregiving is an energy-enhancing experience, increased self-efficacy). Higher scores on the burnout subscale (10 items) indicate the individual is at risk of experiencing symptoms of burnout (e.g., hopelessness, helplessness). Alpha scores range from .72 (burnout) to $.80(\mathrm{CF})$ and $.87(\mathrm{CS})$, indicating adequate internal consistency. The scale has good demonstrated construct validity, and there is evidence that this version of the measure reduced the known collinearity between compassion fatigue and burnout (Stamm, 2005).

Providers were also asked to self-identify if they had specialized training in trauma work and to specify the type of training they had received. To control for overconfidence bias, these responses were compared with the "best-practice" guidelines described previously. If the respondent identified specialized trauma training in any of the identified empirically based methods, the respondent was categorized as having specialized trauma training for the purposes of this study. Additionally, if the provider reported professional experience in a trauma treatment center (inpatient or outpatient), then the individual was characterized as a provider with specialized trauma training. Using this criterion, the rate of agreement between study evaluators and respondent self-identification was $73 \%$. In general, respondents tended to overidentify themselves as trauma specialists if they had personal histories that were positive for trauma exposure and if they had related but non-trauma-related training experiences (i.e., ethics training, training in the assessment and treatment of other conditions such as depression or substance misuse).

A series of items aimed at identifying personal and professional characteristics of each respondent were also included. These questions solicited information about the provider's age, gender, 
years of professional experience, discipline, highest degree earned, and work setting. Respondents were also asked to identify their county of practice so that rural and urban comparisons could be made.

Using the Beale code classification system (Butler \& Beale, 1994), respondents were assigned a code of 0 to 9 that provided a descriptor of their county of practice: metropolitan area of 1 million or more (0), fringe county of metropolitan area of 1 million or more (1), county in metropolitan area of 250,000 to 1 million (2), county in metropolitan area of less than 250,000 (3), urban population of 20,000 or more adjacent to metro area (4), urban area of 20,000 or more not adjacent to metro area (5), urban area of 2,500 to 19,999 adjacent to metro area (6), urban area of 2,500 to 19,999 not adjacent to metro area (7), completely rural area of less than 2,500 adjacent to metro area (8), and completely rural areas of less that 2,500 not adjacent to metro area (9).

\section{Results}

\section{Provider Characteristics}

The average age was 45.22 years $(S D=10.84)$, with a range from 23 to 81 years of age. The majority of professionals $(68.6 \%)$ had master's degrees and, on average, the participants had 13.92 $(S D=9.54)$ years of experience, with approximately $30 \%$ of their clients experiencing post-trauma distress. Over one third of the respondents $(35.8 \%)$ worked in community mental health settings, while $13.6 \%$ worked in other public agencies, $29.6 \%$ were in private practice, $6.2 \%$ worked in inpatient facilities, $4.9 \%$ worked in private facilities, and $9.9 \%$ other worked in settings. Of the 1,121 respondents, $327(30.4 \%)$ were male and $749(69.6 \%)$ were female. This trend held true for every discipline but psychiatrists, who were overrepresented by males (at $52 \%)\left(\chi^{2}=8.98, d f=5, p<.01\right)$. Otherwise, there were no statistically significant differences in age $\left(\chi^{2}=.05, d f=5, p=.89\right)$, setting $\left(\chi^{2}=1.95, d f=4, p=.178\right)$, or caseload $\left(\chi^{2}=3.26, d f=3.62, p=.09\right)$ considering discipline.

\section{Incidence of Compassion Fatigue, Compassion Satisfaction, and Burnout}

In general, this sample fared better on the ProQOL subscales than reported national norms (Stamm, 2005). The CF mean score of 
10.64 in this sample was lower than the national mean of 13 , with $13.2 \%$ of the respondent pool in our sample scoring above the suggested cutoff $(75 \%)$. On the burnout subscale, the national mean is reported as 23, compared to our sample mean of 19.9. Again, just over $13 \%$ scored above the cutoff on the burnout subscale. The potential for CS was slightly higher in our sample than reported national norms $(39.3 \%$ vs. $37 \%)$, with almost half $(48.7 \%)$ of our sample scoring above the suggested cutoff of 41 . Although these national estimates are approximates, they provided an important contextual backdrop for subsequent analyses.

\section{Differences by Provider Characteristics}

A multivariate analysis of variance (MANOVA) was conducted on $\mathrm{CS}, \mathrm{CF}$, and burnout by gender (male vs. female). Tests of homogeneity of covariance matrices using Box's $M$ test and homogeneity of variance assessed by Levene's test were all nonsignificant. The MANOVA revealed simultaneous differences on these three dependent variables by gender, $F(3,1054)=7.10$, $p<.001$ (eta $=.02$, power $=.98$ ). Table 1 shows the univariate analyses of variance (ANOVAs), where CF and burnout differed by gender; females had greater scores on these variables than males.

A MANOVA was conducted on $\mathrm{CS}, \mathrm{CF}$, and burnout by highest degree (bachelor's vs. master's vs. PhD vs. MD). Box's M tests of the equality of the group covariance matrices and Levene's robust test of the homogeneity of variance were significant. However, Stevens (1996) states that sums of 50 or more observations approximate normality, "as long as group sizes are approximately equal (largest/smallest 1.5), $F$ is robust" (p. 249), and "it is very unlikely that the equal covariance matrices assumptions would ever literally be satisfied in practice" (p. 251).

Given the unequal group sizes, participants were randomly deleted to ensure a robust $F$ test. The MANOVA did reveal simultaneous differences on these three dependent variables by degree, $F(9,771)=2.56, p<.01($ eta $=.03$, power $=.94)$. Table 1 also depicts the univariate ANOVAs, where only CF differed by degree. Scheffe's post hoc analyses revealed that MDs had greater $\mathrm{CF}$ scores than both MA and $\mathrm{PhD}$ professionals. No other group differences were found. 


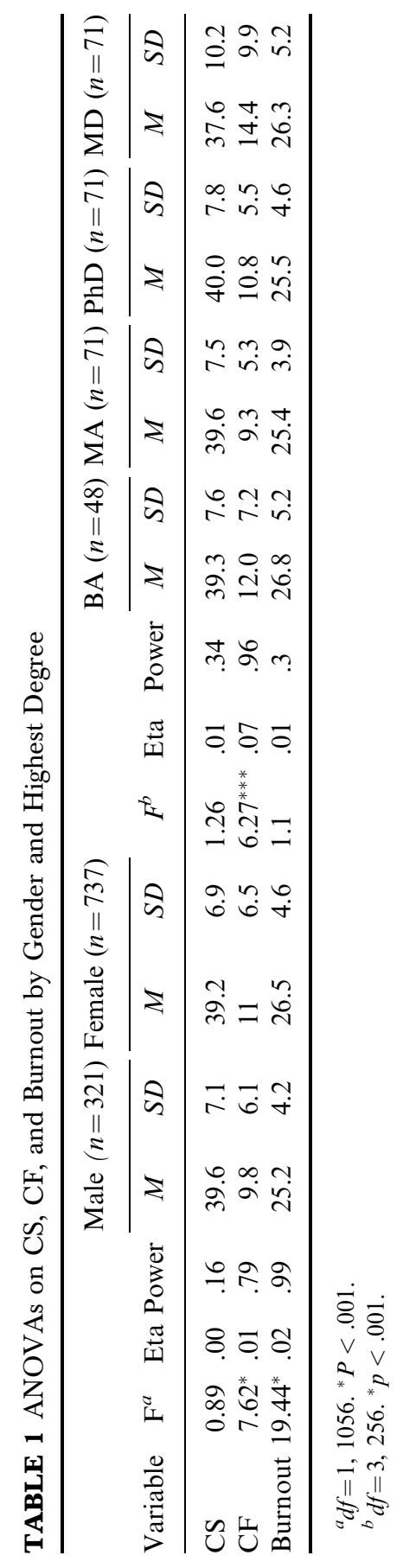


A MANOVA was conducted on $\mathrm{CS}, \mathrm{CF}$, and burnout by licensure (MD, LCSW, CSW, LPCC, LMFT, psychologist, LSW, and CADC). Tests of homogeneity of covariance matrices using Box's $M$ test and homogeneity of variance assessed by Levene's test were significant. The MANOVA revealed simultaneous differences on these three dependent variables by licensure, $F(21,1569)=3.09$, $P<.001$ (eta $=.04$, power $=1.00)$. ANOVAs revealed that $\mathrm{CS}$, $F(7,523)=2.26, P<.05($ eta $=.03$, power $=.84)$, and $\mathrm{CF}, F(7$, $523)=5.20, p<.001($ eta $=.06$, power $=1.00)$, differed by licensure, but not burnout, $F(7,523)=2.02$, ns $($ eta $=.03$, power $=.79)$. Post hoc analyses revealed that MDs had greater CF scores than LCSWs, psychologists, and LSWs at the $\mathrm{P}=.05$ level (Table 2). No other group differences were found.

A MANOVA was conducted on CS, CF, and burnout by type of organization (community mental health, public agency, private nonprofit, inpatient care, other, and private practice). Tests of homogeneity of covariance matrices using Box's $M$ test were significant, while the homogeneity of variance assessed by Levene's test was not significant. The MANOVA revealed simultaneous variation on these three dependent variables by organization, $F(15$, $1548)=1.90, p<.05($ eta $=.02$, power $=.95)$. ANOVAs revealed that $\mathrm{CF}, F(5,516)=2.68, p<.05($ eta $=.03$, power $=.81)$, and burnout, $F(5,516=3.26, p<.01$ (eta $=.03$, power $=.89)$, differed by organization, but not CS, $F(5,516)=1.28$, ns (eta $=.01$, power $=.46)$. Scheffe's post hoc analyses revealed inpatient professionals had significantly higher burnout scores than private practice professionals at the $p=.05$ level (Table 2). No other group differences were found.

A MANOVA was conducted on $\mathrm{CS}, \mathrm{CF}$, and burnout by specialized training (no vs. yes). Box's $M$ test and Levene's test were significant. The MANOVA revealed simultaneous differences on these three dependent variables by specialized training, $F(3,1074)=12.82, p<.001($ eta $=.04$, power $=1.00)$. ANOVAs revealed that $\mathrm{CS}, F(1,1076)=37.09, p<.001($ eta $=.03$, power $=$ $1.00)$, and CF, $F(1,1076)=9.12, p<.01($ eta $=.01$, power $=.86)$, differed by training, but not burnout, $F(1,1076)=0.38$, ns (eta $=.00$, power $=1.00)$. Scheffe's post hoc analyses revealed that those with specialized training had greater CS and lower CF scores than those without specialized training (Table 2). No other group differences were found. 
TABLE 2 Means on CS, CF, and Burnout by Licensure, Type of Organization, Specialized Training, and County

\begin{tabular}{|c|c|c|c|c|c|c|c|}
\hline \multirow[b]{2}{*}{ Variable } & \multirow[b]{2}{*}{$n$} & \multicolumn{2}{|c|}{$\mathrm{CS}$} & \multicolumn{2}{|c|}{$\mathrm{CF}$} & \multicolumn{2}{|c|}{ Burnout } \\
\hline & & $M$ & $S D$ & $M$ & $S D$ & $M$ & $S D$ \\
\hline \multicolumn{8}{|l|}{ Licensure $^{a}$} \\
\hline $\mathrm{MD}$ & 70 & 36.19 & 10.19 & 15.01 & 9.63 & 26.53 & 5.41 \\
\hline LCSW & 74 & 40.12 & 7.8 & 8.64 & 5.13 & 25.07 & 4.05 \\
\hline CSW & 74 & 38.64 & 5.92 & 11.59 & 6.4 & 26.69 & 4.95 \\
\hline LPCC & 71 & 40.32 & 6.14 & 10.73 & 5.72 & 27.11 & 3.7 \\
\hline LMFT & 71 & 39.35 & 8.31 & 11.24 & 7.51 & 25.63 & 4.39 \\
\hline Psychologist & 78 & 38.56 & 6.36 & 10.03 & 6.16 & 25.65 & 3.61 \\
\hline LSW & 48 & 39.06 & 8.96 & 10.06 & 6.33 & 26.73 & 5.94 \\
\hline CADC & 45 & 40.43 & 5.11 & 10.89 & 6.69 & 25.09 & 3.35 \\
\hline \multicolumn{8}{|l|}{ Type of organization $^{b}$} \\
\hline Community mental health & 94 & 39.41 & 7.75 & 10.49 & 7.07 & 26.22 & 4.82 \\
\hline Public agency & 90 & 38.42 & 6.48 & 12.19 & 6.05 & 27.08 & 4.52 \\
\hline Private nonprofit & 92 & 40.63 & 5.38 & 10.4 & 5.29 & 26.37 & 4.04 \\
\hline Inpatient care & 61 & 38.9 & 7.15 & 12.57 & 7.63 & 28.02 & 4.44 \\
\hline Other & 92 & 39.86 & 6.85 & 9.66 & 5.75 & 25.96 & 4.09 \\
\hline Private practice & 93 & 40.17 & 6.81 & 10.48 & 5.62 & 25.45 & 4.03 \\
\hline \multicolumn{8}{|l|}{ Specialized training } \\
\hline No & 633 & 38.18 & 7.46 & 11.14 & 6.69 & 26.13 & 4.52 \\
\hline Yes & 445 & 40.77 & 5.89 & 9.95 & 5.46 & 25.96 & 4.45 \\
\hline \multicolumn{8}{|l|}{ county of practice } \\
\hline Urban & 741 & 39.12 & 0.53 & 10.63 & 0.51 & 19.24 & 6.58 \\
\hline Rural & 126 & 39.77 & 1.89 & 12.36 & 1.93 & 25.78 & 7.07 \\
\hline Rural with urban influence & 139 & 39.45 & 1.45 & 11.9 & 2.78 & 20.97 & 6.23 \\
\hline
\end{tabular}

${ }^{a} \mathrm{CS}: F(7,523)=2.2, p<.05 ; \mathrm{CF}: F(7,523)=5.20, p<.001$; burnout: $F(7,523)=2.02$, NS.

${ }^{b} \mathrm{CS}: F(5,516)=1.28$, NS; CF: $F(5,516)=2.68, p<.05$; burnout: $F(5,516)=3.26$, $p<.01$.

Finally, a MANOVA considering all three criterion variables was conducted to discern possible differences by county of practice using the Beale code designations to create three distinct provider groups, those who practicing in urban, rural, and rural with urban influence settings. Box's M test and Levene's test were not significant. The MANOVA revealed differences by county of practice, $F(1,1006)=2.65, p<.05($ eta $=.954$, power $=1.00)$. ANOVAs revealed that burnout, $F(1,1006)=2.50, p<.05$ $($ eta $=.02$, power $=.913)$, but not CF, $F(1,1006)=1.904, n s$ $($ eta $=.015, \quad$ power $=.803), \quad$ or $\mathrm{CS}, \quad F(1,1006)=.988, \quad$ ns 
(eta $=.008$, power $=.468$ ), differed by practice setting. Bonferroni's post hoc comparisons revealed that respondents who provided services in the most rural areas of the state had higher burnout scores than those in urban areas (see Table 2).

\section{Hierarchical Regression Analysis}

Multiple regression analyses were performed to determine the independent and joint contributions of demographic variables, provider characteristics, practice characteristics, and rurality to the prediction of compassion fatigue, burnout, and compassion satisfaction. Age and gender were entered in the first step of each regression equation as covariates. Provider characteristics (licensure type, highest degree earned, and years of clinical experience) and practice characteristics (percentage of clients suffering from PTSD) were entered as a block in Steps 2 and 3, respectively. Finally, Step 4 included county of residence (by Beale code).

Table 3 displays the correlations between the variables, the standardized regression coefficients $\left(\mathrm{o} \mid\right.$ and the $F, R^{2}$, adjusted

TABLE 3 Regression Models Predicting CF, Burnout, and CS

\begin{tabular}{|c|c|c|c|c|c|c|}
\hline \multirow[b]{2}{*}{ Steps } & \multicolumn{2}{|l|}{$\mathrm{CF}$} & \multicolumn{2}{|c|}{ Burnout } & \multicolumn{2}{|c|}{$\mathrm{CS}$} \\
\hline & $\beta$ & $R^{2} \Delta$ & $\beta$ & $R^{2} \Delta$ & $\beta$ & $R^{2} \Delta$ \\
\hline Demograpics & & $.013^{* *}$ & & $.041^{* * *}$ & & $.044^{* * *}$ \\
\hline Age & -.026 & & -.138 & & .194 & \\
\hline Female gender & .85 & & .012 & & .010 & \\
\hline Provider characteristics & & $.017^{* *}$ & & $.011^{*}$ & & .007 \\
\hline Licensure & -.016 & & -.003 & & -.001 & \\
\hline Degree & .146 & & .115 & & -.089 & \\
\hline Years of experience & -.056 & & -.066 & & .029 & \\
\hline Practice characteristics & & $.20^{*}$ & & $.025^{* *}$ & & $.015^{* *}$ \\
\hline$\%$ of clients with PTSD & .138 & & .028 & & .067 & \\
\hline Rurality & & .00 & & .001 & & .001 \\
\hline Practice country Beale code & -.007 & & .023 & & .027 & \\
\hline$F$ & $5.779^{* * *}$ & & $9.195^{* * *}$ & & $7.893^{* * *}$ & \\
\hline$R^{2}$ & .050 & & .078 & & .068 & \\
\hline Adjusted $R^{2}$ & .042 & & .069 & & .059 & \\
\hline
\end{tabular}


$R^{2}$, and $\Delta R^{2}$ values after entry of all seven predictors. $R$ was significantly different from zero at the end of each step except the fourth step in each regression analysis. After Step 4, with all independent variables in the equation, results were as follows: $R=.22, F(7,881)=$ $5.779, p<.000$, for compassion fatigue, $R=.28, F(7,881)=$ $9.195, p<.000$, for burnout, and $R=.26, F(7,880)=7.893$, $p<.000$, for compassion satisfaction. Female gender, young age, a higher educational degree, less clinical experience, and a higher percentage of clients with PTSD predicted higher levels of CF and burnout. Conversely, older age predicted CS. As shown in the table, the seven variables jointly accounted for $42 \%$ of the variance in the CF domain, $69 \%$ in burnout, and $59 \%$ in the CS domain.

\section{Discussion}

This study focused on levels of CF, CS, and burnout in the general population of mental health providers during the usual course of their professional practice. Other studies have focused on acute exposure effects in mental health responders subsequent to traumatic events such as the Oklahoma City bombing (Landry, 2001; Wee \& Meyers, 2002) and the September 11 attacks (Creamer \& Liddle, 2005) or chronic exposure to high levels of traumatic material among providers whose work is focused only on groups such as sexual violence survivors (Schauben \& Frazier, 1995). This study augments the current literature by exploring $\mathrm{CF}, \mathrm{CS}$, and burnout in a community sample of practitioners whose exposure to traumatized clients more closely resembles that of the general provider population outside the context of a catastrophic event.

Based on prevalence estimates in the literature, our sample scores on the CF subscale that exceed the cutoff (indicating a significant risk of $\mathrm{CF}$ ) are somewhat lower than rates reported in other studies (Meldrum et al., 2002; Wee \& Myers, 2002; Figley, 1995; Frederick, 1986), although no uniform measure of CF or consistent scoring parameters are evident in the empirical literature. The fact that approximately $13 \%$ of the provider population sampled is at high risk of CF or burnout further underscores the importance of ongoing investigation of specific provider or setting characteristics that might impact the development of these conditions. 
The results of multiple analyses of variance were both consistent with and varied from findings described by other investigators. To date, findings regarding the role of gender in the development of CF, CS, and burnout have been equivocal and limited by an overrepresentation of female respondents. In this study, we were able to procure a reasonable gender distribution with no significant differences in work setting, which negated the possibility that differential work settings produced variance in responses between males and females. Notably, female gender enhanced the risk of suffering from $\mathrm{CF}$ and burnout, a finding consistent with studies conducted by Kassam-Adams (1999) and Meyers and Cornille (2002). Previous studies that differ with this finding also varied in sample characteristics (Pearlman \& MacIan, 1995), focused on non-U.S. populations (Meldrum et al., 2002), or focused on disaster-specific responses (Wee \& Myers, 2002). Each of these sampling conditions might have introduced special risk factors or cultural influences that created variation in results. While this study did not specifically query participants regarding their personal history of trauma, the finding of a gender-specific female vulnerability to stress responses is robust across many studies, including those involving trauma-exposed samples. There is little reason to propose that enacting general clinician roles would provide special protection or a buffering effect that would extinguish this relationship. Sex-role socialization and its influence on female vulnerability to this type of professional distress and on a respondent's proclivity to disclose symptomatolgy are also important considerations for future research, and must be explored before any definitive statements can be made about the role of gender in the development of $\mathrm{CF}$ and burnout.

Interestingly, in a trend similar to that noted by Ortlepp and Friedman (2002), we found that specialized trauma training did enhance CS and reduce levels of CF and burnout, suggesting that knowledge and training might provide some protection against the deleterious effects of trauma exposure. One implication of this finding is that specialized training enhanced clinician self-efficacy through cultivation of more effective assessment and treatment skills; these clinicians might have experienced treatment outcomes that were superior to their counterparts with less expertise in trauma work. Additionally, training experiences potentially created peer support and even transitory support from colleagues 
that were protective against $\mathrm{CF}$ and burnout, especially for those clinicians working in isolated settings.

Like other studies, our investigation revealed that the caseload percentage of PTSD clients that clinicians treated predicted their levels of $\mathrm{CF}$ and burnout. It is important to remember that clients with trauma and loss issues suffer from severe symptoms that can exact a significant toll on clinicians who work with them over the long haul. It is traditional practice wisdom to develop an optimal "caseload mix" that includes clients presenting with "easier"problems who ameliorate the extreme challenge of working with those presenting with more "difficult," and in some cases "intractable," problems.

Clinicians in our sample who were working in rural locations were more likely to suffer burnout than those in highly metropolitan locations. This finding is understandable in the context of the President's New Freedom Commission on Mental Health's (2003) analysis reporting that rural areas endure "chronic shortages" of mental health professionals and that rural residents tend to seek mental health services later in the course of their illnesses, with more persistent and disabling symptoms, and require more intensive treatment (p. 51). Limited resources, geographical isolation, few colleagues (limited peer support), and highly demanding caseloads create a "perfect storm" of burnout risk among rural clinicians. This is not a new finding for rural mental health researchers, but it is impressive in its reappearance in this specific study, as it does not appear that rural clinicians required high levels of specific exposure to traumatized patients to become chronically distressed. The general duties, burdens, and stressors of rural work appeared to generate burnout (but not CF) and might have prevented the development of empathy and engagement that was necessary to increase vulnerability to CF. In this way, interestingly, burnout might have acted as a protective factor, interfering with the development of empathy and thereby interfering with the transmission of distress.

An unexpected finding was that psychiatrists in our sample experienced higher levels of CF than other professionals. Recognizing that physicians are at risk for certain stress-related conditions is not novel and, in fact, seems logical given the demands of their work. The general medical literature contains numerous studies regarding the high incidence of various conditions such 
as depression, substance misuse, posttraumatic stress, lethality, and interpersonal problems among physicians, (Miller \& McGowen, 2000; Robinson, 2003; Sonneck \& Wagner, 1996. Many of these studies also explored the high levels of burnout reported by physicians, and at least one supported a link between physicians' levels of work-related stress and their higher mortality rates (Korkeila et al., 2003; Hawton et al., 2001). Another investigation discovered that psychiatrists as a group have a higher risk for experiencing patient suicide than a comparable group of mental health professionals (Chemtob, Bauer, Hamada, Pelowski, \& Muraoka, 1989).

This finding of higher rates of CF among psychiatrists illuminates many other conditions that were likely contributing to the problems experienced by physicians in this sample. For example, psychiatrists were delivering intensive care to high numbers of traumatized patients in the context of a severe shortage of psychiatrists in the state where this survey was conducted. This shortage has resulted in higher patient caseloads (even more than their nonmedical counterparts) and fewer medical colleagues with whom to share the burden. The elevations in CF scores for psychiatrists did not appear to be a function of age or practice setting, as there were no statistically significant differences in these demographic variables by discipline. Furthermore, the observed gender effects for the total sample did not hold true for the physicians. The increased $\mathrm{CF}$ levels in this predominantly male group point to the robustness of discipline as a significant contributor to CF.

Public and nonprofit mental health settings are the default locus of treatment for low-income and minority patients; therefore, psychiatrists in these clinics, hospitals, and crisis stabilization units experience exposure to the most distressed patients (especially those with primary or comorbid trauma spectrum disorders). Additionally, according to the laws regulations, and agency policies that guide clinical practice, psychiatrists are the de jure medical decision makers; in this role, they are seen as primarily responsible for managing high-risk situations within a very limited mental health service infrastructure. These events might be a component of the critical exposure mechanisms that resulted in elevated CF.

These grim realities suggest the need for primary prevention efforts in medical school curriculums and residency programs. Inadequate physician preparation could lead to disrupted expectations or even ongoing cognitive dissonance regarding practice 
situations. One commentary from the medical literature notes that due to managed care concerns impacting the operations of university psychiatry clinics, there are decreasing opportunities for psychiatry residents to have the long-term exposure to patients necessary for psychotherapy training (Kay, 1996). Because psychotherapy training includes skill building in managing affective experiences and countertransference, absence of such training might leave physicians less able to manage the stress levels they will encounter when working with demanding patients after graduation. Expertise in pharmacology is not protective against the emotional toil exacted when working intensively with traumatized persons. These issues merit further investigation.

Study limitations should be noted. Our survey methodology required us to limit the number of items we could include, so potentially significant variables (e.g., personal trauma history, habitual coping approaches, exposure to trauma type, and frequency and quality of clinical supervision) were not included in the instrument. While we were able to use a sampling frame of the universe of licensed mental health professionals in the state, we were unable to sample paraprofessionals and nonprofessionals who delivered mental health services to traumatized clients; their responses might have shed light on the relationship between education and CF, burnout, and CS. Furthermore, while the $19.5 \%$ response rate for the survey is within the respectable parameters of survey methodology, nonresponders might have introduced variation in our results in ways we cannot infer. Finally, it is possible that social desirability might have been a confounding factor in the providers' self-report responses, perhaps flowing from an implied "double standard of adjustment" (Kilburg, Nathan, \& Thoreson 1986) whereby mental health professionals are expected to personally and professionally function at higher levels than their patients. Even so, there was little risk associated with honestly selfdisclosing given the anonymous nature of the survey, a condition that should have dampened the social desirability effect.

With these caveats in mind, important information about CF, $\mathrm{CS}$, and burnout was obtained that suggests possible interventions to assist clinicians working with traumatized patients. For example, specialized trauma training appears to provide clinicians with some protection against $\mathrm{CF}$ and enhances CS. Organizations that work with traumatized patients are well advised to incentivize such 
training and continuing education opportunities. Educating clinicians about risk and protective factors, as well as providing resources to enhance protection, might help reduce levels of $\mathrm{CF}$ and burnout; rural providers and psychiatrists might especially benefit from such assistance. While organizational and managed care pressures often appear to preclude capacity management and caseload mix development, renewed efforts in these areas, especially for clinicians treating patients with trauma and loss issues, would not only be humane but probably cost-effective in the long run if they prevent staff turnover, lost time at work, and protective disengagement.

\section{References}

Abu-Bader, S. H. (2000). Work satisfaction, burnout, and turnover among social workers in Israel: A causal diagram. International Journal of Social Welfare, 9, 191-200.

Adams, K. B., Matto, H. C, \& Harrington, D. (2001). The traumatic stress institute belief scale as a measure of vicarious trauma in a national sample of clinical social workers. Families in Society: The Journal of Contemporary Human Services, 82, 363-371.

Baldwin, J. (1963). The fire next time. New York: Dial Press.

Boscarino, J. A., Figley, C. R., \& Adams, R. E. (2004). Compassion fatigue following the September 11 terrorist attacks: A study of secondary trauma among New York social workers. International Journal of Emergency Mental Health, 6, 110.

Brady, J. L., Guy, J. D.,Poelestra, P. L., \& Brokaw, B. F. (1999). Vicarious traumatisation, spirituality, and the treatment of sexual abuse Survivors: A national survey of women psychotherapists. Professional Psychology: Research and Practice, 30, 386-393.

Butler, M. A. \& Beale, C. L. (1994). Rural-urban continuum codes for metro and nonmetro counties, 1993. Beltsville, MD: Agriculture and Rural Economy Division, Economic Research Service, U.S. Department of Agriculture.

Chemtob, C. M., Bauer, G. B., Hamada, R. S., Pelowski, S. R., \& Muraoka, M. Y. (1989). Patient suicide: Occupational hazard for psychologists and psychiatrists. Professional Psychology: Research and Practice, 20, 294-300.

Cornille, T. A. \& Meyers, T. W. (1999). Secondary traumatic stress among child protective service workers: Prevalence, severity, and predictive factors. Traumatology, 5, Article 2. Retrieved from http: \\www.fsu.edu/ trauma/art2v5il.htm

Creamer, T. L. \& Liddle, B. J. (2005). Secondary traumatic stress among disaster mental health workers responding to the September 11 attacks. Journal of Traumatic Stress, 18, 89-96.

Cunningham, M. (2003). Impact of trauma work on social work clinicians: Empirical findings. Social Work, 48, 451-459. 
Dane, B. (2000). Child welfare workers: An innovative approach for interacting with secondary trauma. Journal of Social Work Education, 36, 27-38.

Figley, C. R. (1995). Compassion fatigue: Coping with secondary traumatic stress disorder in those who treat the traumatized. New York: Brunner/Mazel.

Figley, C. R. (2002a). Compassion fatigue: Psychotherapists' chronic lack of self care. JCLP/In Session: Psychotherapy in Practice, 58, 1433-1441.

Figley, C. R. (2002b). Treating compassion fatigue (Vol. 24). New York: BrunnerRoutledge.

Follette, V. M., Polusny, M. M., \& Milbeck, K. (1994). Mental health and law enforcement professionals: Trauma history, psychological symptoms, and impact of providing services to child sexual abuse survivors. Professional Psychology: Research and Practice, 25, 275-282.

Fothergill, A., Edwards, D., \& Burnard, P. (2004). Stress, burnout, coping, and stress management in psychiatrists: Findings from a systematic review. International Fox, R. J., Crask, M.R., E Kim, J. (1988). Mail survey response rate: A meta-analysis of selected techniques for inducing response. Public Opinion Quarterkt, 52, 467-491. Journal of Social Psychiatry, 50, 54-65.

Fox, R. J., Crask, M. R., \& Kim, J. (1988). Mail survey response rate: A metaanalysis of selected techniques for inducing response. Public Opinion Quarterly, 52, 467-491.

Frederick, C. (1986). Psychic trauma in victims of crime and terrorism. In G. R. Vandenbos \& B. Bryant (Eds.), Cataclysms, crises and catastrophes: Psychology in action. Washington, D.C.: American Psychological Association.

Hawton, K., Clements, A., Sakarovitch, C., Simkin, S., \& Deeks, J. J. (2001). Suicide in doctors: A study of risk according to gender, seniority and speciality in medical practitioners in England and Wales, 1979-1995. Journal of Epidemiology and Community Health, 55(5), 296-300.

Holtz, T. H., Salama, P., Cardozo, B. L., \& Gotway, C. A. (2002). Mental health status of human rights workers, Kosovo, June 2000. Journal of Traumatic Stress, 15(5), 389-395.

Imai, H., Nakao, H., Tsuchiya, M., Kuroda, Y., \& Katon, T. (2004). Burnout and work environments of public health nurses involved in mental health care. Occupational and Environmental Medicine, 61, 764-768.

Jenkins, S. R. \& Baird, S. (2002). Secondary traumatic stress and vicarious trauma: A validational study. Journal of Traumatic Stress, 15, 423-432.

Kassam-Adams, N. (1999). The risks of treating sexual trauma: Stress and secondary trauma in psychotherapists. In B. H. Stamm (Ed.), Secondary traumatic stress: Self-care issues for clinicians, researchers, and educators (2nd ed.). Lutherville, MD: Sidran Press.

Kay, J. (1996). New challenges to the faculty in the education of psychiatrists. Bulletin of the Menninger Clinic, 60, 285-295.

Kilburg, R. R., Nathan, P. E., \& Thoreson, R. W. (Eds.)(1986). Professionals in distress: Issues, syndromes, and solutions in psychology (pp. 53-75). Washington, DC: American Psychological Association.

Korkeila, J. A., Toyry, S., Kumpulainen, K., Toivola, J. M., Rasanen, K., \& Kalimo, R. (2003). Burnout and self-perceived health among finnish 
psychiatrists and child psychiatrists: A national survey. Scandinavian Journal of Public Health, 31, 85-91.

Landry, L. P. (2001). Secondary Traumatic Stress Disorder in the therapists from the Oklahoma City bombing. Dissertation Abstracts International, 61, 3849.

Maslach, C. (1982). Burnout, the cost of caring. Englewood Cliffs, NJ: Prentice Hall. Maslach, C. \& Jackson, S. E. (1984). Burnout in organizational settings. In S. Oskamp (Ed.), Applied social psychology annual (Vol. 5, pp. 133-153). Beverly Hills, CA: Sage.

McCann, I. L. \& Pearlman, L. A. (1990a). Psychological trauma and the adult survivor: Theory, therapy, and transformation. New York: Brunner/Mazel.

McCann, I. L. \& Pearlman, L. A. (1990b). Vicarious traumatization: A framework for understanding the psychological effects of working with victims. Journal of Traumatic Stress, 3, 131-149.

Melamed, Y., Szor, H., \& Bernstein, E. (2001). The loneliness of the therapist in the public outpatient clinic. Journal of Contemporary Psychotherapy, 3l, 103-112.

Meldrum, L., King, R., \& Spooner, D. (2002). Secondary traumatic stress in case managers working in community mental health services. In C. R. Figley (Ed.), Treating compassion fatigue (pp. 85-106). New York: Brunner-Routledge.

Meyers, T. W. \& Cornille, T. A. (2002). The trauma of working with traumatized children. In C. R. Figley (Ed.), Treating compassion fatigue (Vol. 24, pp. 39-55). New York: Brunner-Routledge.

Miller, M. N. \& McGowen, R. (2000). The painful truth: Physicians are not invincible. Southern Medical Journal, 93, 966-973.

Nelson-Gardell, D. \& Harris, D. (2003). Childhood abuse history, secondary traumatic stress, and child welfare workers. Child Welfare, 82, 5-27.

New Freedom Commission on Mental Health. (2003). Achieving the promise: Transforming mental health care in America. Rockville, MD: Authour.

Ortlepp, K. \& Friedman, M. (2001). The relationship between sense of coherence and indicators of secondary traumatic stress in non-professional trauma counselors. South African Journal of Psychology, 31, 38-46.

Ortlepp, K. \& Friedman, M. (2002). Prevalence and correlates of secondary traumatic stress in workplace lay trauma counselors. Journal of Traumatic Stress, 15, 213-222.

Pearlman, L. A. \& Maclan, P. S. (1995). Vicarious traumatization: An empirical study of the effects of trauma work on trauma therapists. Professional Psychology: Research and Practice, 26, 558-565.

Pearlman, L. A. \& Saakvitne, K. W. (1995). Trauma and the therapist: Countertransference and vicarious traumatization in psychotherapy with incest survivors. New York: Norton.

Pryce, J. G., Shackelford, K. K., \& Pryce, D. H. (2007). Secondary traumatic stress and the child welfare professional. Chicago: Lyceum Books.

Roberts, R. S. B., Flannelly, K. J., Weaver, A. J., \& Figley, C. R. (2003). Compassion fatigue among chaplains, clergy, and other respondents after september 11th. Journal of Nervous and Mental Disease, 191, 756-758.

Robinson, G. E. (2003). Stresses on women physicians: Consequences and coping techniques. Depression and Anxiety, 17, 180-189. 
Rohland, B. M. (2000). A survey of burnout among mental health center directors in a rural state. Administration and Policy in Mental Health, 27, 221-237.

Schauben, L. J. \& Frazier, P. A. (1995). Vicarious trauma: The effects on female counselors of working with sexual violence survivors. Psychology of Women Quarterly, 19, 49-64.

Sonneck, G. \& Wagner, R. (1996). Suicide and burnout of physicians. Omega: Journal of Death and Dying, 33, 255-263.

Sprang, G. et al. (in press). Factors impacting trauma treatment practice patterns: The convergence/divergence of science and practice. Journal of Anxiety Disorders.

Stamm, B. H. (1997). Work-related secondary traumatic stress. PTSD Research Quarterly, 8(2), 1-3.

Stamm, B. H. (2002). Measuring compassion satisfaction as well as fatigue: Developmental history of the compassion fatigue and satisfaction test. In C. R. Figley (Ed.), Treating compassion fatigue (pp. 107-119). New York: Brunner-Routledge.

Stamm, B. H. (2005). The professional quality of life scale: compassion satisfaction, burnout, and compassion fatigue/secondary trauma scales. Latherville, MD: Sidran Press.

Stevens, J. P. (1996). Appiled multivariate statistics for the social sciences (3rd ed.). Mahwal, NJ: Erlbaum.

Vredenburgh, L. D., Carlozzi, A. F., \& Stein, L. B. (1999), Burnout in counseling psychologists: Type of practice setting and pertinent demographics. Counselling Psychology Quarterly, 12, 293-302.

Webster, L. \& Hackett, R. K. (1999). Burnout and leadership in community mental health systems. Administration and Policy in Mental Health, 2, 387-399.

Wee, D. F. \& Meyers, D. (2002). Stress responses of mental health workers following disaster: The Oklahoma City bombing. In C. R. Figley (Ed.), Treating compassion fatigue (Vol. 24, pp. 57-83). New York: Brunner-Routledge.

Ginny Sprang is the Buckhorn Professor of Child Welfare and Children's Mental Health at the University of Kentucky. Dr. Sprang received her Ph.D from the University of Texas in 1991 and served as a visiting associate professor in the Department of Psychiatry at the University of Colorado Health Science Center, Irving Harris Program in Child Development and Infant Mental Health, during her sabbatical in 2003-2004. She is considered a national expert on child trauma and children's mental health.

Adrienne Whitt-Woosley is a clinical social worker and adjunct professor at the University of Kentucky. Her clinical work focuses on serving children and families impacted by maltreatment, and she is the project director for the UK Behavioral Health Disaster Response Project. This project provides research and training for health care professionals statewide and nationally regarding disaster response strategies and trauma intervention. 
James J. Clark is an associate professor and associate dean for research at the University of Kentucky with appointments in the College of Social Work and the College of Medicine (Department of Psychiatry). He is a licensed clinical social worker with practice and research specializations in forensic mental health, child maltreatment, and substance misuse. He is also a principal investigator with the UK Comprehensive Assessment and Training Services Project. 
Copyright of Journal of Loss \& Trauma is the property of Routledge and its content may not be copied or emailed to multiple sites or posted to a listserv without the copyright holder's express written permission. However, users may print, download, or email articles for individual use. 